\title{
Constructivism in Practical Philosophy
}

\section{Citation}

Scanlon, Thomas. 2012. Constructivism in Practical Philosophy. In Constructivism in Practical Philosophy, ed. James Lenman and Yonatan Shemmer, 226-242. Oxford: Oxford University Press.

\section{Published Version}

doi:10.1093/acprof:oso/9780199609833.003.0013

\section{Permanent link}

http://nrs.harvard.edu/urn-3:HUL.InstRepos:17543101

\section{Terms of Use}

This article was downloaded from Harvard University's DASH repository, and is made available under the terms and conditions applicable to Other Posted Material, as set forth at http:// nrs.harvard.edu/urn-3:HUL.InstRepos:dash.current.terms-of-use\#LAA

\section{Share Your Story}

The Harvard community has made this article openly available.

Please share how this access benefits you. Submit a story.

Accessibility 


\title{
The Appeal and Limits of Constructivism $^{1}$
}

\author{
T. M. Scanlon
}

In 1982, I wrote the following.

There is such a subject as moral philosophy for much the same reason that there is such a subject as the philosophy of mathematics. In moral judgments, as in mathematical ones, we have a set of putatively objective beliefs in which we are inclined to invest a certain degree of confidence and importance. Yet on reflection it is not at all obvious what, if anything, these judgments can be about, in virtue of which some can be said to be correct or defensible and others not. This question of subject matter, or the grounds of truth, is the first philosophical question about both morality and mathematics. Second, in both morality and mathematics it seems to be possible to discover the truth simply by thinking or reasoning about it. Experience and observation may be helpful, but observation in the normal sense is not the standard means of discovery in either subject. So, given any positive answer to the first question-any specification of the subject matter or ground of truth in mathematics or morality - we need some compatible epistemology explaining how it is possible to discover the facts about this subject matter through something like the methods we seem to use. ${ }^{2}$

I went on to say that in the case of morality there is also a third question: "Given any candidate for the role of subject matter of morality, we must explain why anyone should care about it." I will call this the question of practical significance: why we should regard moral demands as ones we have strong reason to accept as guides to conduct.

In the case of normative truths, worries underlying the first two questions I have listed were famously stated by John Mackie. Stating a version of the question of subject matter, Mackie wrote that, "if there were objective values, then they would be entities or qualities or relations of a very strange sort, utterly different from anything else in the universe." ${ }^{3}$ And, addressing the epistemological question, he went on to say that if we

\footnotetext{
${ }^{1}$ I am grateful to Peter Koellner and Charles Parsons for very helpful comments on an earlier version of this paper.

2 Scanlon 1982, p. 104.

${ }^{3}$ Mackie 1977, p. 38. In fairness to Mackie, I should emphasize that, like most people discussing these issues at the time he was writing, he was concerned with morality, not with practical reasons more generally.
} 
were aware of these facts about such a subject matter "it would have to be by some special faculty of moral perception or intuition, utterly different from our ordinary ways of knowing everything else." He continued

When we ask the awkward question, how we can be aware of this authoritative prescriptivity, of the truth of these distinctively ethical premises or of the cogency of this distinctively ethical pattern of reasoning, none of our ordinary accounts of sensory perception or introspection or the framing and confirming of explanatory hypotheses or inference or logical construction or conceptual analysis, or any combination of these, will provide a satisfactory answer; "a special sort of intuition" is a lame answer, but it is the one to which the clear-headed objectivist is compelled to resort. ${ }^{4}$

I believe that Mackie states the question of subject matter in an overly metaphysical way. In neither the case of mathematics nor that of the normative is it a problem that facts about these domains would be different from facts about the natural world. There is no reason to believe that the only truths are truths about the natural world. Nor is it "incompatible with a scientific view of the world" (i.e. that world) to maintain that there are such truths. ${ }^{5}$

Even if this is so, however, there remain important questions about the subject matter of mathematics and that of morality and of the normative more generally, questions that an account of these domains should answer. These are, first, questions about whether these subject matters can be characterized in a way that justifies confidence that claims about them have determinate truth-values. Second, there is the question of in what sense truths about these domains are "independent of us." Third, there is the epistemological question of how it is possible for us to come to know truths about the subject so characterized. This is not a problem of explaining how we can be in touch with strange entities, but rather a question of determining what methods of first-order reasoning about that subject matter should be seen as valid. Finally, in the case of morality there is the question of practical significance-the problem of explaining the importance that moral truths have for us.

When he speaks of claims about objective values, he may intend to contrast these with claims about "subjective" values - claims about what a person ought to do, or has reason to do, that, unlike moral claims, are claimed to hold only insofar as the agent has certain desires or aims. Mackie may have no objection to values, or claims about reasons, of the latter kind. If so, however, his position suffers certain instability. The claim that a person has reason to do what will promote the satisfaction of his or her desires is itself a normative claim. Indeed, it is an "objective" normative claim, since it does not itself depend on what people desire, or on what aims they have. If there is something metaphysically odd about objective normative truths, then this supposed truth (that people have reason to do what would satisfy their desires, or promote their aims) is just as odd as any other. The disagreement between someone who thinks that all reasons for action depend on the agent's desires and someone who thinks that there are some reasons that do not depend on agents' desires is a normative disagreement, not a metaphysical one. So Mackie's "argument from queerness," insofar as the queerness involved is metaphysical, is an argument against irreducibly normative truths of any kind, not just objective moral values. At least this is how I am going to take his argument, I hope not unfairly.

${ }^{4}$ Ibid., p. 39.

${ }^{5} \mathrm{I}$ argue for these claims in my 2009 John Locke Lectures, Scanlon, forthcoming. 
Many of these questions could, I believe, be satisfactorily answered by a sufficiently clear characterization of the subject matter of a domain in first-order terms - that is, in the terms used by ordinary statements in that domain. The subject matter of arithmetic, for example, is adequately characterized by saying that it includes zero and all and only those other numbers reached from zero by repeated applications of the successor function. This characterization seems evidently true and non-arbitrary. Since the truth-values of arithmetical statements are determined, ultimately, by facts about the successor relation, this characterization supports the idea that arithmetical statements have determinate truth-values (unless this description of an infinite domain is seen as unintelligible). We are capable of thinking about and comparing particular finite strings in this sequence, $S O, S S O \ldots$ so it is not mysterious how we can arrive at basic truths of arithmetic "just by thinking about them." Moreover, on the basis of this characterization of the domain, we can recognize as true more general axioms (such as Peano's postulates), which can then be used to establish general theorems about numbers. Gödel's results show that any set of axioms, if consistent, will leave some sentences undecided, but this does not mean that the sentences that are undecidable in a particular axiom system have no determinate truth-value.

This is in contrast with the situation in set theory, where there is at present no fully satisfactory general characterization of the domain of sets. This domain might be characterized in two ways. The first is through sets of axioms, such as those of Zermelo-Frankel set theory (ZF). But even if these axioms are plausible and, as far as we can see, consistent, they may seem arbitrary in the absence of some general characterization of the realm of sets that they describe, and which supports them in the way in which our intuitive understanding of the natural numbers supports the Peano postulates.

One such characterization is provided by what is called the iterative conception of set. ${ }^{6}$ According to this conception, the universe of sets consists of just those that would be formed in the following process: Begin, at stage 0 , with a finite list of specified elements (or with the empty set). At stage $n+1$ form all sets of the basic elements and the sets that were created at previous stages. For each limit ordinal $\lambda$, at stage $\lambda$ form the set of all sets formed at stage $\alpha$ for all $\alpha<\lambda$. The iterative conception provides a rationale for most of the standard axioms of accepted set theory. As I have stated it, the account is vague or incomplete in a number of ways. First, it appeals at various points to the idea of "all sets" "formed" at previous stages, and these ideas seem to need further specification. ${ }^{7}$ Second, it remains unspecified how far the construction extends (through "all" of the transfinite ordinals?)

\footnotetext{
${ }^{6}$ On this conception and the adequacy of the basis it provides for axioms of set theory, see Shoenfield 1977; Boolos 1971; Parsons 1983; and Boolos 1989

7 As Parsons notes (Parsons 1983), there are also questions about how the idea of "earlier and later" in the sequence is to be understood.
} 
The more serious problem, however, is that neither this conception nor the axioms of $\mathrm{ZF}$ seem to give a complete characterization of the realm of sets. Important questions are left open, such as the status of the continuum hypothesis - the question of whether there are transfinite sets that are larger than the set of all natural numbers but smaller than the set of all sets of natural numbers. To resolve this question, and others, we need a further characterization of the realm of sets. This might be provided by additional axioms, or by augmenting the description offered by the iterative conception. This might be done by changing the starting point-beginning with something other than the empty set-or by redefining the steps through which the hierarchy proceeds. Ideally, one would want to do both: to find additional axioms that are supported by an augmented version of this hierarchical process.

These additional axioms, and the characterization supporting them, would be justified by its ability to unify and explain what seem to be the most evident truths about sets. As Kurt Gödel famously observed:

There might exist axioms so abundant in their verifiable consequences, shedding so much light on a whole field, and yielding such powerful methods for solving problems ... that, no matter whether they are intrinsically necessary, they would have to be accepted at least in the same sense as a well-established physical theory. ${ }^{8}$

It appears that the ultimate form of justification here is a process like what Rawls called the method of reflective equilibrium: we look for general principles that unify and explain what seem to us to be the most evident truths about a subject matter, being ready along the way to change our mind about these "evident truth" when we learn more about what general principles would be required to explain them. ${ }^{9}$ So, for example, we might be led to change our mind about the continuum hypothesis when we discover that it can only be supported by additional axioms that have other consequences that are very implausible. As Rawls said about the search for principles of justice:

Moral philosophy is Socratic: we may want to change our present considered judgments once their regulative principles are brought to light. And we may want to do this even though these principles are a perfect fit. A knowledge of these principles may suggest further reflections that lead us to revise our judgments. ${ }^{10}$

We may hope that this process of seeking reflective equilibrium will lead to a set of axioms and a general characterization of the realm of sets that fit together in a satisfactory way. This would not be a metaphysical account of the subject matter of set theory: it would proceed entirely in first-order terms, employing the concept of a set. Despite this, such an account would support the idea that set theory has a

\footnotetext{
8 Gödel 1964, p. 477.

9 See Rawls 1971, sec. 9 and "The Independence of Moral Theory" in Rawls 1999.

10 Rawls 1971, p. 49.
} 
determinate subject matter, and that statements about sets have determinate truthvalues, removing the sense that the choice of set theoretic axioms is arbitrary. But it remains possible that this process will not lead to any single overall account of the realm of sets but instead to several alternative accounts shaped by different additional axioms. In this case a kind of pluralism about set theory may be correct: there may be alternative characterizations of the domain of sets between which it is open to us to choose. ${ }^{11}$

The case of morality is in some important respects analogous to that of set theory in this regard: we lack a single convincing overall first-order characterization of the subject matter of morality (analogous to the characterization of the natural numbers). The search for such a characterization must proceed by the method of reflective equilibrium, but this method may not yield a single determinate answer. Indeed, the situation of morality seems worse than in that of set theory in one important respect: the concepts in question cannot be characterized with sufficient precision to provide a rigorous account of the methods of reasoning that we employ in carrying out the search for reflective equilibrium.

I have so far been considering the advantages that could be gained from a comprehensive characterization of the subject matter of a domain in purely first-order terms: by means of general claims about numbers, about sets, or about what is morally right and wrong. Let me now turn to the idea that such an account might be constructivist. A constructivist account, in the sense in which I will be using that term, characterizes a domain in terms of some specified process of construction. This can take many different forms. The process in question may involve ways of constructing objects in the domain of a particular kind - for example, a way of constructing a number $a$ such that $F a$ or a general way, given a number, $b$, of constructing a number $a$ such that $R b a$. But since the result of such a construction is always to establish the correctness of some statement about the domain, such as " $F a$," or " $\exists x F x$," or " $R b a$ " or “ $(x) \exists y R x y$," we can think of the constructions not as ways of constructing objects but as ways of establishing particular claims about a domain. This will be a constructivist account of the domain (rather than merely a set of general truths about that domain) only if it is plausible to think that what makes something a truth about the domain in question is that it can be arrived at through steps of the kind in question.

A constructivist account will be interesting only if it specifies clearly which sequences of steps constitute a construction (or derivation) of the appropriate kind. Deciding whether a given step is of an appropriate kind may involve an exercise of judgment. But (and this is the point that justifies this seeming digression) the judgment that is called for cannot be a judgment directly about the truth of some claim about the domain in question, or about what seems most likely to be true about this domain. A procedure that involves judgments of this kind may be a way of arriving at justified

11 A possibility described in Koellner 2010. 
beliefs about a domain. But such a process could not be what determines the facts about that domain itself.

It follows that the process of seeking a set of beliefs about a subject that are in reflective equilibrium may be a way of arriving at a characterization of the subject matter of a domain, but it is not an account of that subject matter itself, and, in particular, not a constructivist account. This is because that process-identifying those statements about the subject that seem most clearly true, formulating general principles that would account for those truths, then going through successive steps of modifying judgments and principles to find ones that fit together properly-requires repeated judgments about the domain in question.

In the case of mathematics, the term 'constructivist' is generally used in a sense that is more limiting than the one I am here concerned with. The appeal of accounts that are constructivist in this sense lies in concern about characterizations of a domain in terms of a "completed infinite" such as "the set containing 0 and closed under successor." It may be held that we cannot grasp the idea of such a set, and perhaps even that this description does not identify a determinate domain. Doubts of this kind lead people to seek an account according to which the facts about numbers are facts about what has been or could actually be arrived at by us through certain specified means of construction. This leads to a different view of the methods of valid reasoning about numbers, and to the conclusion that statements about numbers may not all have determinate truth-values, since for a given $A$ there may be no construction leading to $A$ and yet no construction leading to not- $A$.

Things are different in the case of morality, because the source of doubts about this domain is different. A characterization of the subject matter of morality consisting simply of very general first-order principles of right and wrong may seem unsatisfactory for a variety of reasons. Insofar as these principles are claimed to be true independent of us, one may want some explanation of what kind of facts these are. This problem is sharpened by the problem of practical significance. If moral truths are truths about a domain of facts independent of us, why should we take these facts to be significant, even authoritative, as guides to conduct? If moral truths were true in virtue of facts about us, such as our preferences, or our wills, then their practical significance for us could be readily explained. But if they are objective truths, independent of us, then it may well be asked why we should care about them. This fundamental tension between objectivity and practical significance was a central element in Mackie's challenge: what he expressed skepticism about was the possibility of facts "in the world" that had what he called "objective prescriptivity."

Some constructivist accounts of morality are appealing because they seem well positioned to respond to this problem. To see why, consider first the account offered by John Rawls, who was the first to introduce the term "constructivism" in this area. ${ }^{12}$

12 In Rawls 1980 and Rawls 1993, Lecture III,"Kantian Constructivism in Moral Theory,” and Political Liberalism, Chapter III, "Political Constructivism." 
Rawls was concerned not with morality in general but with justice, that is to say, principles for the assessment of basic social institutions. The function of such principles, he believed, is to serve as a shared basis for assessing conflicting claims from citizens about what their institutions should be like. The main conflicts of this kind will be between individuals in different economic classes and between individuals who have different religious views or, more generally, different "conceptions of the good." So principles appropriate for this role will need to be justified on a basis that is neutral with respect to these forms of disagreement. Rawls suggested that this would true of principles that would be agreed to by parties who did not know what economic class they represented or what conception of the good they held. He made this idea more precise in his idea of an Original Position in which principles of justice are chosen. ${ }^{13}$

The resulting view, that the correct principles of justice are ones that would be agreed to by parties in the Original Position Rawls described, has the form of a constructivist view: facts about justice are facts about what principles would be arrived at through a process of a certain kind. Even though Rawls defines his Original Position quite clearly, deciding what principles of justice would or could be chosen in such a position requires the exercise of judgment. (This is an important contrast with the case of set theory.) But the account remains constructivist because the judgments in question are not judgments about what is just or unjust (or morally right or wrong) but rather judgments about what individuals who are seeking only to do as well for themselves as they can would have reason to choose under conditions of limited knowledge.

The case for accepting this constructivist account of justice lies with a reflective equilibrium argument. The account has to be defended by claiming that it "fits with" and provides a satisfying explanation of what are, on reflection, our considered judgments about justice. ${ }^{14}$ These include judgments "of all levels of generality"judgments about the justice or injustice of particular institutions and practices, maxims stating prima facie just- or unjust-making characteristics, and judgments about the nature and role of justice itself. ${ }^{15}$

The fact that certain principles would be chosen through a procedure of the kind Rawls described gives us reason to be concerned with them because it indicates that they have the kind of impartial justification that makes them fit to play the role that principles of justice are supposed to play. This is only a partial explanation, since it can always be asked what reason we have to be concerned with impartial justifications of this kind. The answer is given, I believe, by pointing to the character that our relations

13 Rawls 1971, Chapter III.

14 "On reflection" because the relevant class of judgments is not fixed at the start. Our assessment of which judgments are "considered" is likely to change as the process of seeking principles that explain these judgments goes forward. For more discussion, see Scanlon 2002, my "Rawls on Justification."

${ }^{15}$ See Rawls 1951; Rawls 1971, sec. 9; and Rawls 1975. For further discussion see Scanlon 2002. 
with our fellow citizens have if we are cooperating with them on principles that have such a justification, compared with the character of these relations when our institutions cannot be justified in this way. The force of this appeal can, of course, be debated further (every justification has to start somewhere). But the fact that it can be supported by this explanation takes the constructivist account beyond what is offered by a firstorder account that takes the form simply of general principles specifying what justice requires.

This constructivist account also offers an explanation of the objectivity of claims about justice - the sense in which they are correct or incorrect "independent of us." To assess this explanation we should consider first the various ways in which the idea of independence can be understood.

The first is the idea that a subject matter is "independent of us," and judgments about it are objective, if it is possible for us (at least individually) to be mistaken in our judgments about it. Call this minimal objectivity judgment-independence. Truths of arithmetic and set theory are objective in this sense. Why do I believe that they are? Because there are ways of thinking about these questions which anyone who understands the subject can engage in, and which seem to lead clearly to certain conclusions. These "ways of thinking" need not be algorithms, although in the case of arithmetic they often are. More informal methods-such as those we use to convince ourselves of many of the axioms of set theory-can suffice. This minimal objectivity (judgmentindependence) is not just a matter of de facto agreement, but also the tendency of the judgments of different competent judges to converge, and the stability of our own judgments, which supports our confidence that they concern judgment-independent truths. It is important, for example, that there is such a thing as discovering errors in our thinking, and that when we have identified something as an error this conclusion is generally stable — we do not generally flip back the other way.

Judgment-independence is an important property, but it is a quite minimal notion of objectivity. Even judgments about what is the case according to a make-believe game can be objective in this sense, as can judgments about what is permitted by certain social norms. But these things are not "independent of us" in at least one of the senses that we have in mind in discussing objectivity.

A second, stronger idea is that a subject matter is independent of us, and judgments about it are objective, if these judgments are minimally objective and, in addition, the standards for assessing such judgments do not depend on what we have done, chosen, or adopted, and would not be different had we done, chosen, or adopted something else. I will call this choice-independence. Judgments about what one has reason to do in a make-believe game and judgments about what one has to do given arbitrary social norms are judgment-independent but not choice-independent. To be clear: judgments about what is true within such a game, or what is required by a social norm, can be both judgment-independent and choice-independent. What are not choice-independent are judgments about what one has reason to do or believe that presuppose these games or norms. 
Many mathematical judgments, such as propositions of number theory and arithmetic, are objective in both of these senses. Many axioms of set theory (such as the standard Zermelo-Frankel axioms) are choice-independent as well as judgment-independent. But if "pluralism" of the kind mentioned earlier turns out to be correct then there are further axioms of set theory that are not choice-independent.

I believe that many judgments about reasons for action are both judgmentindependent and choice-independent, although there is disagreement about whether this is so. But even if judgments about reasons are independent of us in both of these senses they are not "independent of us" in the further sense of being independent of what we are like. This might be called independence of human nature. If we were constituted or situated differently, so as to have different needs, or so as to enjoy different things, then our reasons would be different. In the case of reasons, lack of independence in this sense does not seem to be a problem. One would not expect or want them to be independent of our nature in this way. (Mathematical truths, on the other hand, might be expected to have this kind of independence, although it is an interesting question how it would matter if they lacked it.)

What does seem clear, however, is that the significance of mathematical truths does not depend on their being independent of us in any further, distinctively ontological sense of having a real existence apart from us. Facts about physical objects do need to have such an existence. But there is, I believe, no reason to construe mathematical truths on this model.

According to Rawls's constructivist account, judgments about justice are objective in the sense of being judgment-independent if judgments about what parties in Rawls's Original Position have reason to choose, and judgments about what follows from those principles, are judgments we can be mistaken about. This seems quite plausible. Judgments about what the parties in the Original Position would have reason to choose are normative judgments. But their objectivity is less controversial than that of many normative judgments, because they are only hypothetical normative judgments-judgments about what parties have reason to do given certain specified aims and given certain background information. These judgments are in this respect like the judgments I mentioned above, such as judgments about games or social norms, which have judgment-independence but lack choice-independence. This is not, however, a flaw from the point of view of the aims of a constructivist theory.

As I said earlier, the appeal of a constructivist theory lies in the promise of giving an account of a subject matter that supports the idea that judgments about it have determinate truth-values and that provides or fits with a plausible account of the practical significance of such judgments. The fact that, on such an account, the determinate truth-value of judgments about justice depends on the choice of a particular way of defining the Original Position is not a problem if the fact that a principle would be arrived at in an Original Position of that kind is a reason for us to give that principle the authority claimed for principles of justice. 
A claim that being chosen in such an Original Position is a reason to regard a principle as authoritative is an unconditional normative claim about what we have reason to do in the relevant circumstances, hence more controversial than the conditional claims about what parties in the Original Position would have reason to choose, given their aims and the information available to them. But this should not undermine the determinateness of judgments about justice on this constructivist account, even for a person who has doubts about the objectivity of unconditionally normative judgments. What we have, then, is a two-part thesis: an account of the truth-values of judgments about justice, which depends only on conditional normative claims, and an account of the significance of such judgments, which depends on claims about reasons whose objectivity may be more controversial.

Any suggestion of arbitrariness flowing from the dependence of the truth-values of judgments about justice on the choice of a particular way of defining the Original Position would be further reduced, or even eliminated, I would say, if a larger reflective equilibrium argument establishes that the account of justice provided by this definition is the one that best fits with all of our considered judgments about justice. (It is exactly the lack of such an argument that could lead to a "pluralist" view of set theory.)

My own contractualist account of moral right and wrong could also count as a constructivist account (in this case, an account of individual morality). ${ }^{16}$ According to this account, in order to determine whether an action is morally permissible we should consider a general principle that would permit it. We then consider what objections individuals in various situations could offer to this principle based on the way in which they would be affected by it, by living with the consequences of the actions it would permit and with the possibility that agents may perform such actions, since they would be permitted to do so. We then compare these reasons with the reasons that individuals would have to object to a principle that would forbid actions of the kind in question, based, again, on how they would be affected by such a principle, and consider whether it would be reasonable for those who have reason to object to the principle permitting the action to reject it, given the reasons that others have for objecting to the contrary principle. If it would be reasonable to reject that principle, then the action in question would be morally wrong. The rightness or wrongness of an action depends on what the correct outcome of this procedure would be, whether or not anyone has carried it out.

Like Rawls's constructivist account of judgments about justice, this account of the subject matter of moral rightness and wrongness makes the truth-values of judgments about this subject matter depend on facts about what principles individuals in certain circumstances would have reason to reject. It then explains the practical significance of judgments about right and wrong on the ground that we have reason to care about principles that could not be rejected in this way-specifically, that we have reason to

16 See Scanlon 1998, Chapters 4, 5. 
care about this kind of justifiability of our actions to others. The case for accepting this account of rightness and wrongness then depends, as before, on a reflective equilibrium argument that it provides the best overall account of our considered judgments about this subject matter, including, as before, judgments "of all levels of generality," not just judgments about the rightness and wrongness of particular actions.

On this account, judgments of right and wrong will have a particular form of objectivity — will be judgment-independent or choice-independent—just in case judgments about what individuals in certain circumstances have reason to reject have these forms of objectivity. In contrast to Rawls's constructivist account of justice, in this case the judgments on which the truth-values and objectivity of moral judgments are made to depend are fully normative judgments about reasons for action. They are judgments about what individuals in specified circumstances who, among other things, care about finding principles others could also accept, would have reason to do. But the judgments that are called for involve judgments about which things individuals have more reason to want to have, or to avoid. Since someone like Mackie, who has doubts about the objectivity of moral judgments is likely to have doubts about the objectivity of judgments about reasons for action in general, this brings us to the general question of how the determinateness and objectivity of judgments of the latter kind can be explained and defended. In particular, it raises the question of whether a constructivist view might provide a satisfactory account of the subject matter of normative judgments in general.

Such an account would involve a process for "constructing" reasons-that is, for arriving at conclusions about whether a given consideration is or is not a reason for a person in certain circumstances to act in a certain way-such that there are determinate standards for the validity of steps involved in this process. Moreover, for reasons mentioned above, the validity of these steps cannot depend on the truth of claims about which things are or are not reasons for action.

If such an account of reasons for action is to have ambitions parallel to those of constructivist accounts of justice and moral rightness and wrongness, the fact that the conclusion that $P$ is a reason for a person in $C$ to do $A$ can be arrived at through this process should help to explain the practical significance of a claim that $P$ is a reason. In this case, however, it is not clear what is to be explained. The practical significance of judgments about justice or about moral right and wrong can be seen as lying in the fact that when such a judgment is correct then we have reason to be guided by it in deciding what to do. So in these cases practical significance can be explained in terms of reasons. But where judgments about reasons for action are concerned this is not an option. It is nonsensical to ask what reason we have to do what we have reason to do. So if the practical significance of judgments about reasons is to be explained this must take some other form. ${ }^{17}$ Finally, if a constructivist account of reasons for action is to be supported

17 For fuller discussion of this question see Scanlon, forthcoming, Lecture 1. 
in reflective equilibrium, it should seem evident that at least those judgments about reasons that seem most clearly correct are ones that could be arrived at through the procedure that this account describes.

Although I think that constructivist accounts of justice and morality have some plausibility, I do not believe that a plausible constructivist account of reasons for action in general can be given. In the remainder of this chapter I will try to explain why.

The best-known attempt to provide such a view is what has come to be called Kant's Categorical Imperative procedure. ${ }^{18}$ Kant's Categorical Imperative is a test of the acceptability of maxims, which I will take to be general policies of taking certain considerations as reason to act in certain ways. A maxim passes the Categorical Imperative test if it can be willed to be a universal law or if adopting it is consistent with regarding rational nature (whether one's own or that of another rational creature) as an end in itself. This is commonly understood as a test of the moral acceptability of a maxim, and of acting on such a maxim. So understood, it seems too weak to provide a general account of reasons for action since, presumably, it can be permissible for a person to do things that, as it happens, he or she has no reason to do. In Korsgaard's version of the Kantian account, this gap is filled by the idea of an agent's practical identities. A practical identity is "a description under which you value yourself and find your life worth living and your actions to be worth undertaking. Conceptions of practical identity include such things as roles and relationships, citizenship, memberships in ethnic or religious groups, causes, vocations, professions, and offices." ${ }_{19}$

The overall idea is this: insofar as we see ourselves as acting at all, we must see the Categorical Imperative as constraining our practical thought. So we have the reasons specified by the maxims that this requires us to adopt. Beyond this, we have reasons to do those things that are required by the more specific practical identities we have adopted, provided that these are compatible with the Categorical Imperative. This view can be seen as constructivist insofar as it provides a procedure through which it is determined whether something is a reason for a person: something is a reason for a person if denying that it was a reason would violate the Categorical Imperative or be inconsistent with some practical identity (consistent with the Categorical Imperative) that that person has adopted. ${ }^{20}$ The fact that valid judgments about reasons arise from this process is supposed to explain their practical significance: their special authority lies in the agent's own will —in the fact that they flow from choices the agent has made or from an identity that an agent must endorse insofar as she sees herself as acting at all.

According to this account, judgments about reasons are objective in the sense of being judgment-independent: they are the kind of thing that someone can be mistaken

\footnotetext{
${ }_{18}$ See Korsgaard 1996; O’Neill 1989.

19 Korsgaard 2009, p. 20.

20 This account could also be seen as constructivist insofar as it holds that we construct the domain or reasons by adopting particular ends and practical identities, in ways consistent with the Categorical Imperative. This seems to me entirely consistent with the version stated in the text so I will not explore it separately.
} 
about. Some judgments about reasons - those following from the Categorical Imperative itself-are also choice-independent. The reasons flowing from the choices of practical identity that the agent has made will not be choice-independent. Whether this is a flaw in the account, or an advantage, is something to be determined by the process of seeking reflective equilibrium in our overall judgments about reasons. It is quite plausible to say that some reasons a person has depend on prior choices he or she has made. The question is when this is true and how this dependence is best explained.

I cannot here give a full examination of the Kantian theory, which is subtle and complex, but will just state briefly my reasons for finding it unsatisfactory. ${ }^{21}$ First, despite the initial appeal of various forms of Kant's Categorical Imperative as moral requirements, I am not convinced by any arguments I have seen for the claim that we must see these requirements as binding on us insofar as we see ourselves as acting at all. Second, although it seems true that individuals have different reasons depending on the ends and practical identities they have adopted, these reasons depend on their having good reasons to adopt those ends or identities in the first place, and not to revise or reject them. And these reasons in turn are not all adequately explained by the Categorical Imperative test.

If the Kantian constructivist account of reasons is not satisfactory, is there another constructivist account that would be more satisfactory? Part of the appeal of the Kantian account is that it not only promises to provide grounding for the correctness of judgments about reasons but also promises to do this in a way that explains the practical significance of these judgments. It attempts to do this by grounding facts about reasons in a conception of rationality. So one question is whether there might be a different conception of rationality that could play this grounding role. This would have to be a conception that did not itself involve or depend on substantive claims about what reasons people have, but which led to conclusions about such claims. I do not myself see what such a conception could be like. Some things that are referred to as conceptions of rationality are very general substantive theses about reasons - such as the idea that it is rational for a person to do what is in his or her self-interest. Such an account could not serve as an explanation of the practical significance of these reasons. The only non-substantive alternative that I am aware of is the formal conception of rationality discussed by John Broome and others, according to which rational requirements are simply requirements of consistency among a person's practical attitudes. ${ }^{22}$ These requirements have no substantive implications about the reasons people have. So no account of either of these kinds would provide a basis for claims about reasons.

It is possible, however, that there might be a constructivist account of reasons of a less ambitious kind. Such an account would keep the ambition of characterizing the domain of reasons in a way that supported the idea that judgments about reasons have determinate truth-values. But it would abandon the further aim of explaining the

\footnotetext{
${ }^{21}$ For slightly fuller discussion see Scanlon 2011

${ }^{22}$ See Broome 1999, 2005; Kolodny 2005.
} 
practical significance of conclusions about reasons, resting simply with the idea that the "normative authority" of a reason is simply that - being a reason — and that this cannot be explained any further way. Such an account would be similar to the "constructivist" account of sets offered by the Iterative Conception. This account characterizes the universe of sets by describing the way in which sets are constructed out of sets or nonset elements. But it is stated in the language of set theory, and does not claim to explain what a set is. Might there, then, be a constructivist account of reasons of this more modest kind?

It does seem that some reasons depend on others. Roughly speaking, it seems that if a person has good reason to have a certain end, then he or she has good reason to do what will promote it, and if a person has good reason to hold a certain value, or to adopt a particular practical identity, then he or she has good reason to do what is involved in respecting this value or living in accord with this identity. ${ }^{23}$ One might say, then, that these relations of dependence between reasons are ways in which the domain of reasons is determined, by the construction of some reasons on the basis of others. The problem, however, is that there seem to be too many seemingly independent reasons that are not constructed from others in this way. To refer again to the analogy with set theory, the question would be what is to play the role here analogous to the empty set, or a small set of prior elements from which the domain of sets may be seen as constructed. One proposal might be that the only underived reasons are reasons to avoid pain and seek pleasure, and that all other reasons are constructed out of these in ways like those just described. This does not seem to me a very plausible proposal, because it does not seem that these are the only underived reasons. And this conclusion points toward a more general one: the domain of reasons, even reasons for action, seems too varied and complex to be plausibly analyzed in this way.

How, then, do we come to know particular underived truths about which things are reasons? My own answer is that we do this simply by thinking carefully about what seem to us to be reasons, considering what general principles about reasons would explain them, what implications these would have, considering the plausibility of the implications of these principles and so on. For example, suppose it seems to me that someone has reason to do $A$ because he or she would find it pleasant. Pleasure does not always constitute a reason (pleasure in the suffering of others, for example, does not). So we need to ask what attitudes this particular pleasure involves, and whether they are attitudes that one has reason to want, or reason to want in the particular circumstances in question.

One might characterize this process as one of bringing one's particular judgments about reasons and one's general principles about when something is a reason into reflective equilibrium. This seems to me broadly correct, although misleading in some ways, of which I have space here to mention only a few.

${ }^{23}$ Exactly how this is so is a complicated matter. See Raz 2005 and Kolodny $m s$. 
The first is that the distinction between particular judgments and general principles that explain them is in this case not clear. As I mentioned earlier in discussing pain, the process I have just described is one of coming to a clearer understanding of the conditions, $c$, under which some fact $p$ is a reason. So it is as much a matter of clarifying what particular judgment we in fact accept, as a matter of finding a separate principle that "explains" this judgment. Second, the label "equilibrium" is misleading insofar as it suggests that one's reasons for accepting the judgments one holds at the end of the process include the fact that one has achieved an "equilibrium" or "coherence" among one's various beliefs. ${ }^{24}$ The problem with this is that mere coherence is too easily achieved - one could attain it in many ways, simply by rejecting one or another set of conflicting judgments. The justificatory force of the judgments we arrive at lies, rather, in the details of the process that leads to these judgments. The reason for accepting one of these judgments is that (as far as one can tell) it entails other judgments that are true, or is supported by judgments that lead to such conclusions. (Just as, in the case of set theory, one has reason to accept a new axiom because it supports or is supported by and unifies other set theoretic claims that appear to be correct.)

These factors being noted, it seems to me that such a process of careful reflection is the only way we have of arriving at conclusions about reasons for action. Might this process itself be seen as a constructivist account of the domain of reasons? Sharon Street, for example, speaks of "a constructivist view according to which the truth of ' $X$ is a reason for agent $A$ to $Y$ ' is a function of whether that judgment would be among $A$ 's evaluative judgments in reflective equilibrium." 25

There are several problems with this proposal. First, it is not plausible to claim that if the judgment that $X$ is a reason for $A$ to $Y$ would be among $A$ 's evaluative beliefs in reflective equilibrium then $X$ is a reason for $A$ to $Y$ however A carried out the process of reaching this equilibrium. There are many lazy and sloppy ways of reaching equilibrium. As I just pointed out, the normative status conferred by a judgment's being in a set that is in reflective equilibrium depends on the quality of the decisions that are made in arriving at it - decisions about what to count as a considered judgment at the outset and about what to modify in situations of conflict. So the most that could be said is that $X$ is a reason for $A$ to $Y$ if the judgment that it is such a reason would be among $A$ 's evaluative judgments in reflective equilibrium if the judgments A made in arriving at this equilibrium were sound. So understood, however, this is not a constructivist view, since the steps involved in carrying out the process in question would involve making judgments about what is or is not a reason.

Leaving aside the question of the applicability of the label "constructivist," however, it is true for the same reason that the process of seeking reflective equilibrium in one's beliefs about reasons is not an account of the subject matter of practical reasons at all. In deciding whether a certain claim is among one's "considered judgments," or in

\footnotetext{
${ }^{24}$ For fuller discussion see Scanlon $2002 . \quad{ }^{25}$ Street 2006, p. 110.
} 
deciding whether to modify such a judgment in the light of its conflict with a principle one has arrived at or whether, instead, to modify or abandon the principle in the light of this conflict, the question one asks cannot be "Will this judgment be among those I would arrive at if I reached reflective equilibrium?" but rather "Is this judgment correct?" The process of seeking reflective equilibrium in one's beliefs about a subject matter is therefore not a characterization of the truth about that subject matter but rather a method for arriving at such a characterization.

\section{References}

Barwise, Jon (ed). 1977. Handbook of Mathematical Logic (Amsterdam: North Holland).

Benacerraf, Paul and Hilary Putnam (eds). 1983. Philosophy of Mathematics: Selected Readings, Second edition (Cambridge: Cambridge University Press).

Boolos, George. 1971. "The Iterative Conception of Set," in Benacerraf and Putnam, 1983, pp. 486-502.

Boolos, George. 1989. "Iteration Again," in Philosophical Topics 42, pp. 5-21.

Broome, John. 1999. “”Normative Requirements," in Ratio 12, pp. 398-419.

Broome, John. 2005. "Does Rationality Give Us Reasons?" in Philosophical Issues 15, pp. 321-37.

Buneo, Otavio and Oystein Linnebo (eds). 2009. New Waves in Philosophy of Mathematics (Houndmills: Macmillan Publishing).

Freeman, Samuel (ed.). 2002. The Cambridge Companion to Rawls (Cambridge: Cambridge University Press).

Gödel, Kurt. 1964 “What Is Cantor's Continuum Problem?” in Benacerraf and Putnam, 1983, pp. $470-85$.

Koellner, Peter. 2010. "Truth in Mathematics: The Question of Pluralism," in Buneo and Linnebo, 2010, pp. 80-117.

Kolodny, Niko. 2005. "Why Be Rational?" in Mind 114, pp. 509-63.

Kolodny, Niko. Unpublished ms. "Toward a Principle of Instrumental Transmission".

Korsgaard, Christine. 1996. The Sources of Normativity (Cambridge: Cambridge University Press).

Korsgaard, Christine. 2009. Self-Constitution: Agency, Identity, and Integrity (Oxford: Oxford University Press).

Mackie, J. L. 1977. Ethics: Inventing Right and Wrong (Harmondsworth: Penguin).

O’Neill, Onora. 1989. Constructions of Reason (Cambridge: Cambridge University Press).

Parfit, Derek. 2011. On What Matters (Oxford: Oxford University Press).

Parsons, Charles. 1983. "What Is the Iterative Conception of Set?" in Benaceraf and Putnam, 1983, pp. 503-29.

Rawls, John. 1951. "Outline of a Decision Procedure for Ethics," in Rawls, 1999, pp. 1-19.

Rawls, John. 1971. A Theory of Justice (Cambridge, MA: Harvard University Press).

Rawls, John. 1980. "Kantian Constructivism in Moral Theory," in Rawls 1999, pp. 303-58.

Rawls, John. 1993. Political Liberalism (New York: Columbia University Press).

Rawls, John. 1999. Samuel Freeman, ed., Collected Papers (Cambridge, MA: Harvard University Press). 
Raz, Joseph. 2005. "The Myth of Instrumental Rationality," in Journal of Ethics and Social Philosophy 1, pp. 1-28.

Scanlon, T. M. 1982. "Contractualism and Utiliarianism," in Sen and Williams 1982, pp. 103-129.

Scanlon, T. M. 1998. What We Owe to Each Other (Cambridge, MA: Harvard University Press). Scanlon, T. M. 2002. "Rawls on Justification," in Freeman, 2002, pp. 139-67.

Scanlon, T. M. 2011. "How I Am Not a Kantian,” in Parfit, 2011, volume 2.

Scanlon, T. M. Forthcoming. Being Realistic about Reasons.

Sen, Amartya and Williams, Bernard (eds). 1982, Utilitarianism and Beyond (Cambridge: Cambridge University Press).

Shoenfield, J. R. "Axioms of Set Theory," in Barwise, 1977, pp. 321-44.

Street, Sharon. 2006. "A Darwinian Dilemma for Realist Theories of Value," in Philosophical Studies 127, pp. 109-66. 